\title{
Effects of aerobic exercise and drug therapy on blood pressure and antihypertensive drugs: a randomized controlled trial
}

\author{
*Maruf $\mathrm{FA}^{1}$, Akinpelu $\mathrm{AO}^{2}$, Salako $\mathrm{BL}^{3}$ \\ 1. Department of Medical Rehabilitation, Faculty of Health Sciences and Technology, Nnamdi Azikiwe University, Nnewi \\ Campus, Nnewi, Nigeria \\ 2. Department of Physiotherapy, Faculty of Clinical Sciences, University of Ibadan, Nigeria \\ 3. Nephrology Unit, Department of Medicine, Faculty of Clinical Sciences, University of Ibadan, Nigeria
}

\begin{abstract}
Background: Although aerobic exercise has been shown to lower blood pressure (BP) in human beings, its additive BPreducing effect on antihypertensive drug therapy seems to have been investigated in only laboratory animals.

Objectives: This study investigated the effects of aerobic dance combined with antihypertensive drugs on BP and number of antihypertensive drugs in individuals with hypertension.

Methods: This open label randomised-controlled trial involved new-diagnosed male and female individuals with mild-tomoderate essential hypertension after at least four weeks of treatment. They were randomly assigned to drug therapy (Normoretic: Hydrochlorothiazide + amiloride hydrochloride, and Amlodipine) (control: $\mathrm{n}=33$ ) and aerobic dance combined with drug therapy (exercise: $\mathrm{n}=30$ ) groups. Intervention in each group lasted 12 weeks. BP was measured at baseline and during and pos-intervention. Number of antihypertensive drugs was recorded post-intervention.

Results: There were significant reductions in SBP at some periods of the intervention in the exercise group $(\mathrm{p}=0.000$ to 0.002 ) and control group ( $\mathrm{p}=0.001$ to 0.002 ), and significant difference in DBP at some periods of the intervention in exercise group ( $p=0.000$ to 0.003 ) and control group ( $p=0.000$ to 0.001$)$. SBP ( $p=0.066)$ and DBP $(p=0.100)$ did not differ between the two groups post-12-week intervention. The BP control rates were similar between the exercises $(56.7 \%)$ and control $(35.5 \%)$ groups $(p=0.075)$. Similarly, between-group difference in the number of drugs was not significant $(p=0.511)$. Conclusion: This preliminary report demonstrates the tendency of aerobic dance to enhance BP control in individuals on two antihypertensive drugs without BP control.
\end{abstract}

Key words: Aerobic exercise, drug therapy, blood pressure, randomised controlled trial African Health Sciences 2013; (1): 1-9 http://dx.doi.org/10.4314/ahs.v13i1.1

\section{Introduction}

Despite the advances in knowledge and the increasingly effective therapeutic strategies for hypertension management, sustainable control rates at the population level are still elusive ${ }^{1,2}$.

There is growing evidence that uncontrolled hypertension occurs in populations with even good access to health care. ${ }^{3}$ In the US, $29 \%$ of estimated 41.9 million people with hypertension, who were treated for hypertension, had uncontrolled blood pressure (BP). ${ }^{4}$ Even in well-conducted clinical trials, with availability of numerous antihypertensive drugs

\begin{tabular}{|l|}
\hline *Corresponding author: \\
Fatai Adesina Maruf \\
Department of Medical Rehabilitation \\
Faculty of Health Sciences and Technology \\
Nnamdi Azikiwe University \\
Nnewi Campus, Nnewi, Nigeria \\
Tel: +2348067437607 \\
Email: mafaad@yahoo.com \\
\hline
\end{tabular}

African Health Sciences Vol 13 Issue 1 March 2013 and combination therapies, BP control rates could range from only $45 \%$ to $66 \% .^{5,6}$

Uncontrolled hypertension has been reported to be common (27.1\%) among Nigerian patients $^{7}$, and is associated with various degrees of target organ damage with increasing morbidity and mortality. ${ }^{8}$ Blood pressure control was adequate in only $29 \%$ of Nigerian patients despite adequate adherence with drug therapy in $77.5 \%$ of them. ${ }^{9}$ Factors identified to contribute to uncontrolled hypertension among Nigerian patients are female gender, diabetes mellitus and number of daily tablets $>2.7$ The prevalence of refractory or resistant hypertension, which is inadequate $\mathrm{BP}$ control in a patient who complies with 3 drugs in adequate dosage is, however, low (1.1\%) among Nigerian patients. $^{7}$

The association of daily tablets $>2$ with uncontrolled hypertension may be mediated through poor adherence with drug therapy. Kaplan ${ }^{10}$ recommended the use of non-pharmacological 
means, such as aerobic exercise, as effectively as possible so that minimum drug therapy is needed. This may complement the BP-lowering effects of antihypertensive drugs, and thereby, reducing the number or dose of drugs required. ${ }^{11}$ In addition, the efforts devoted to lifestyle modifications, such as physical exercise ${ }^{12}$, are worthwhile since all drugs cost money and may produce side effects. ${ }^{13}$

Considering the fact that aerobic exercise is only effective if it is performed continually ${ }^{14}$, it will not be proper to overlook sustainability in choosing an exercise modality. Possible modalities are walking, jogging or running using a treadmill, riding a bicycle ergometer $^{15,16,17}$, swimming ${ }^{18}$, home aerobics ${ }^{19}$. Considering the built environment in Nigeria and economic situations of many citizens, however, most of these modalities may not be practicable for the majority of people, with the exception of aerobic dance. According to $\mathrm{Kumar}^{20}$, dancing is a hobby that many people take a lot of interest in. Furthermore, dancing is an inexpensive, simple and culturally-friendly modality, and hence can foster sustainability and compliance in terms of performance. It could be carried out in the comfort of home settings, and that could allow for supports in terms of family members' participation.

Blood-pressure-lowering effects of aerobic exercise have been well documented in the literature. ${ }^{17}$, 19, 21, 22 Two previous studies ${ }^{23,24}$ had investigated the additive effect of drug therapy on BP-reducing effect of physical exercise in individuals with moderate hypertension. Furthermore, two laboratory studies ${ }^{25,26}$ investigated the additive effects of physical exercise on BP-reducing effect of drug therapy in spontaneously hypertensive rats. To our knowledge, no human study has investigated the possible additive BP-lowering effect of exercise to achieve BP control in individuals on drug therapy without BP control. In this study, we investigated the effect of aerobic dance combined with antihypertensive drug therapy on BP control and number of antihypertensive drugs taken by individuals with essential hypertension who had been on two antihypertensive drugs without adequate control.

\section{Methods \\ Participants}

Sixty-three individuals with uncontrolled essential hypertension who were recruited from the Hypertension Clinic of the Medical Out-Patient Department of the University College Hospital and out-patient Department of Adeoyo Maternity
Teaching Hospital, both in Ibadan, have so far completed the study. The university College Hospital is a tertiary level hospital whereas Adeoyo Maternity Hospital is a secondary-level hospital partly used for teaching purposes. The individuals were sourced from patients newly diagnosed as having essential hypertension, and were screened for eligibility. Participants were screened with medical history and physical examination as well as laboratory tests before recruiting them into the study. Absence of secondary hypertension was confirmed in all the participants. They were excluded if they were younger than 18years or older than 65 years and if they were pregnant or diabetic or had a history of coronary or valvular heart, renal, cerebral vascular, hepatic, neurological disease or obstructive sleep apnoea. Absence of secondary hypertension was confirmed in all participants using urinalysis, blood chemistry profile (potassium, sodium, creatinine, fasting glucose, fasting lipid levels) and a 12-lead electrocardiogram. Participants with recent history of smoking and alcohol abuse ( $<6$ months) were also excluded. ${ }^{22}$ None of the participants was involved in an exercise training programme during 6 months prior to the study. Eligible participants were placed on one tablet of Normoretic (50mg Hydrochlorothiazide $+5 \mathrm{mg}$ Amiloride Hydrochloride) for 2 weeks. Participants whose BP was not less than $140 / 90 \mathrm{mmHg}$ after two weeks were given an additional drug (5mg of Amlodipine) (Amlovar). At the end of this second two-week period, those whose BP were still above 140/ $90 \mathrm{mmHg}$ but was below the severe hypertensive range $(180 / 110 \mathrm{mmHg})$ were randomly assigned to a study group. The participants whose BP was still above $180 / 110 \mathrm{mmHg}$ had their Amlovar dose increased to $10 \mathrm{mg}$ for another two weeks. After the third two-week period, those with inadequate BP control but had their BP less than 180/110mmHg were again randomly assigned to a study group. In essence, only those who had mild-moderate hypertension after being on one tablet of Normoretic in addition to either $5 \mathrm{mg}$ Amlovar or $10 \mathrm{mg}$ Amlovar for 4 or 6 weeks respectively were finally recruited into this study. Participants gave informed consents to participate in the study following adequate explanation of the procedure to them.

\section{Random Assignment}


Participants were randomly assigned to exercise and control groups using the computer-generated random number. This involved simple randomization to groups. This was achieved by using Research Randomizer (www.randomizer.org). It involved specifying the sets of number (number of groups) and the number in a group, assigning number to the group and specifying the range of the numbers, specify whether to sort the generated number or not and whether each number in a set should remain unique, whether to place marker off, within or across. Then finally we clicked the button to randomize and generate the number for random assignment. We generated one set of 120 non-unique, unsorted number ranging from 1 to 2 (1 for exercise group and 2 for control group). This preliminary report is on 30 participants in the exercise group and 33, in the control group.

\section{Trial design}

This open label randomised-controlled trial was approved by the Ethics Review Committee of University of Ibadan/University College Hospital, Ibadan. All participants were on two antihypertensive drugs at recruitment. All the participants continued their antihypertensive medication throughout the study. Participants in the exercise group underwent aerobic exercise training in addition to their antihypertensive medication.

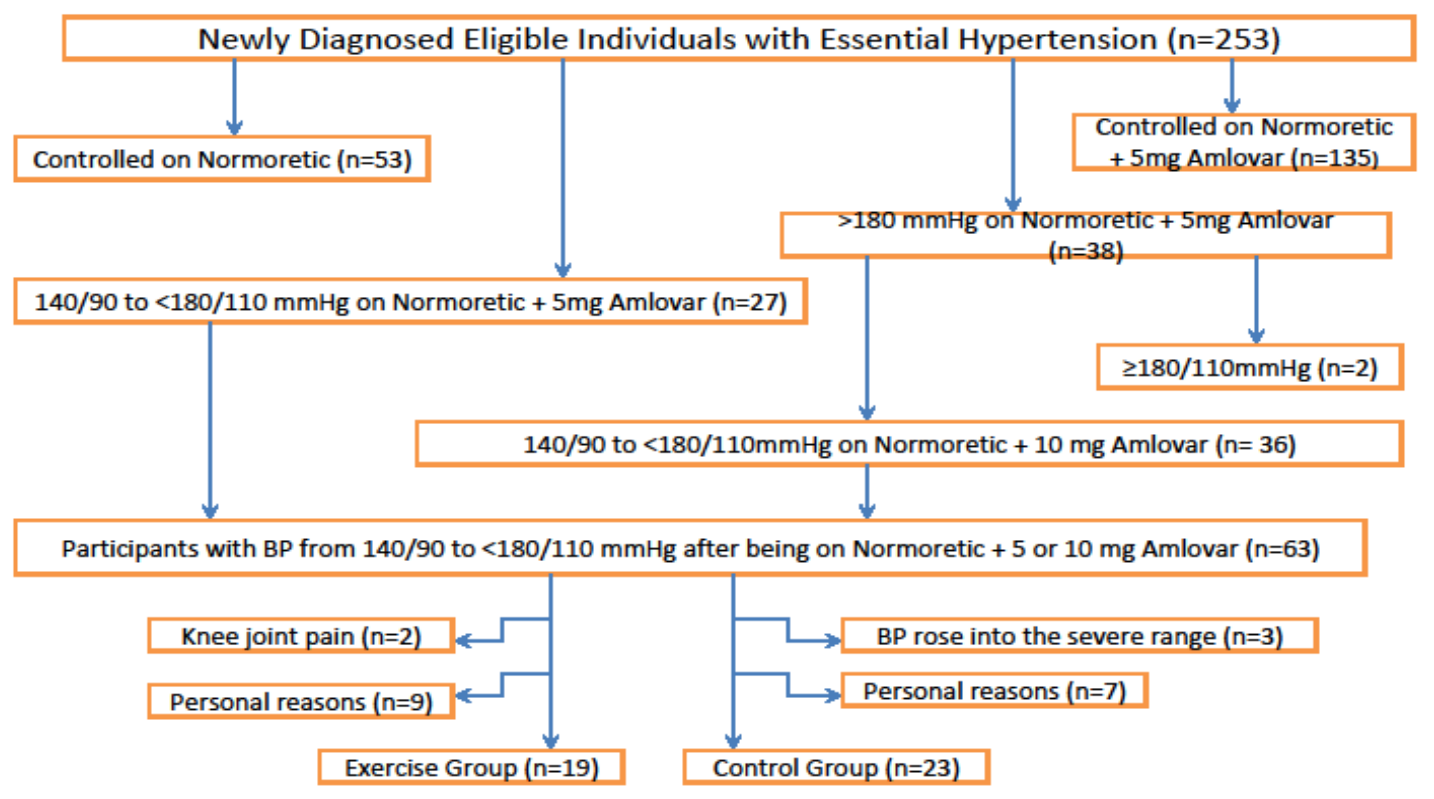

Figure 1: Flow Chart for participants' recruitment

The consultants in charge were blinded to the participants' groups. To achieve this, we agreed that the appointments of participants with the consultants were only on Tuesdays and Thursdays when the participants in the exercise group would not have any exercise session. The consultants modified participants' drugs as necessary. The medication was modified by increasing the dose of Amlovar such that the BP reading of below $180 / 110 \mathrm{mmHg}$ was constantly achieved throughout the study. Participants in both groups were assessed before, at 3-weekly interval, and after the 12-week intervention. Bio-data of the participants, such as age, sex, marital status, and occupation, were recorded. Also recorded were percent body fat, body mass index (BMI), waist circumference, blood lipids, exercise capacity, quality of life and intervention adherence of participants. The research assistant who carried out the measurement was not blinded to the patients' group but since automatic BP monitors were used and the drugs were recorded as prescribed by the consultants, the possibility of biased was reduced. 


\section{Withdrawal criteria}

Participants were withdrawn if they complained of musculoskeletal pain persistently over three sessions or if they showed sign of cardiovascular stress such as dizziness and chest pain during the aerobic dance training. When a patient is on the maximal doses of the two drugs and the BP rose into the severe antihypertensive range persistently over two weeks, the patient was withdrawn from the study. Participants could also withdraw voluntarily at any stage in the two groups. However, apart from people lost to knee-joint pain in the exercise group (two) and elevated BP into severe range in the control group (three), other participants (exercise: $\mathrm{n}=9$; control : $\mathrm{n}=7$ ) who did not finish the intervention did so for personal reasons, most commonly familial commitments or other ailments.

\section{Measurements}

Height of participants was measured using a height meter. Participant stood bare-footed and erect on the standing platform of the scale, looking straight ahead, and the height was read off from the meter at the level of vertex of the head. Weight was measured using a portable weighing scale (Secca, model 762, Germany). The participants were measured barefooted and with minimal clothing. Body mass index was determined from measured height and weight of the participants using the relation: Weight/Height ${ }^{2}$ Percent body fat was measured using fat meter (Omron, HBF-306-E, Japan). This involved feeding participants' weight, height, age, and sex into the fat meter. Holding the meter in both hands such that the electrodes were covered by hands, participants stood erect with feet together and arms held straight forward with elbow and wrist in full extension and at 90 degrees of shoulder flexion. The start button was then pressed and participants was asked to remain still, while the microprocessor of the meter calculated the percent body fat and displayed it on the screen of the meter. Waist Circumference was measured at the level of the umbilicus for the waist circumference using an inelastible tape measure (Butterfly, China).

Blood pressure was measured in the sitting position using an automated BP device (Omron, HEM-712) following the recommended standards. ${ }^{27}$ The readings were separated by 2 minutes. ${ }^{28}$ The number of antihypertensive drugs was counted. All participants were on two drugs- one tablet of Normoretic and 5 or $10 \mathrm{mg}$ of Amlovar.

\section{Aerobic exercise training programme}

The 12-week aerobic exercise training was conducted using a 45-minute exercise dance video at a frequency of 3 sessions per week (Monday, Wednesday and Friday). There were 4-10 participants in a session of aerobic dance class depending on availability of eligible participants to recruits. The participants' heart rate was monitored at interval. Each session of the programme comprised an initial five-minute warm up, 35-minute aerobic dance and final five-minute cool down phases. The warm up and cool down comprised of stretching exercises to the arms, legs and trunk while the aerobic dance incorporated bouncing movement of the leg, forward and backward movement, jumping, shoulder movements, arm stretching, trunk stretching, rolling and bending and hip twisting, chest movement. The intensity and duration of the aerobic dance were progressively increased such that the participants completed 45 minutes per session at $50-70 \%$ heart rate reserve.

\section{Study adherence}

During the 12-week intervention the participants receiving aerobic dance + antihypertensive drug therapy were expected to attend 36 sessions. The participants in the control group came every 3 week for periodic assessment till the 12 week elapsed. During the intervention, participants were given their antihypertensive drugs every three weeks. The drugs were counted for each participant, in plastic cases, such that it will last till the next visits with a few extra. At the next visit, old cases were returned with unused medications, and pills were counted to determine drug adherence. ${ }^{23}$ To maximise adherence to drug prescription, the drugs were given out for free. Further, participants in the exercise group were called twice per week on any two days they were not meant to come for the exercise training, whereas those on the control group were called three times per week on alternate days. Drug adherence was determined by dividing the total number of drugs taken over the twelve-week intervention period with the maximum number of drug possible over the same period and multiplied by 100 . The adherence was determined for each drug, and an average drug adherence for each group was calculated by adding up the two drug adherences and dividing by two.

The adherence to appointment was computed differentially for the exercise and control groups. For the exercise group, the number of sessions attended was divided by the maximum 
number of sessions possible (36) and multiplied by 100. The participants in the control group were coming every three week after the baseline measurements. The number of visits during the intervention period was four. So, the number of visits made divided by four multiplied by 100 constituted the adherence rate. The participants were called on phone, if they failed to show up on ay day they were supposed to come either for exercise training or periodic appointment, to ascertain the reason for their absence, and they were encouraged to be present at the session. In addition, such participants were called on the day just before the next appointment day to remind them of the appointment. The overall adherence was determined by adding up the average drug adherence and the appointment adherence for each group and dividing by two.

\section{Statistical analysis}

The data were analysed using Statistical Package of Social Science (SPSS) version 17. An á level of 0.05 was accepted for statistical significance. Betweengroup comparisons for baseline quantitative variables (age, height, weight, BMI, percent body fat, waist circumference, SBP and DBP) and study adherence were carried out using independent t-test. Betweengroup comparisons of gender distributions and BP control rates were carried out using Chi square. Comparisons of within-group changes in the SBP and DBP, and number of antihypertensive during the interventions were carried out using paired t-test with Bonferroni correction for multiple comparisons. Repeated measure ANOVA was utilised to determine the effect of exercise on SBP, DBP and number of antihypertensive drugs with age, body mass index, percent body fat and adherence used as covariates. Intention-to-treat analysis was used.

The sample size of 120 for this trial was estimated based on BMI, which has the least possible change from physical exercise among the variables measured. The standard difference of variable was estimated to be 0.60 , and percentage point of normal distribution for statistical significance level at $95 \%$ confidence interval was 1.96 . Percentage point of normal distribution for statistical power at $80 \%$ was 0.8416 . About $30 \%$ drop-out rates were envisaged and this was considered to arrive at the sample size.

\section{Results}

\section{Physical characteristics of participants}

Table 1shows physical characteristics of 63 middleaged (exercise: $50.38 \pm 8.4$ years; control: $55.3 \pm 8.1$ years) and overweight (exercise: $28.4 \pm 4.9 \mathrm{~kg} / \mathrm{m} 2$; control: $26.0 \pm 4.1 \mathrm{~kg} / \mathrm{m} 2$ ) participants. The exercise and control groups were not similar only in age $(\mathrm{p}=$ $0.020)$, BMI $(p=0.041)$ and per cent body fat $(p=0.011)$ at baseline (table 1). The distributions of participants across gender were not different between the two groups $(\mathrm{p}=0.641)$.

\section{Table 1: Characteristics of participants}

\begin{tabular}{llll}
\hline & \multicolumn{2}{c}{ Exercise $(\mathbf{n}=32)$} & \multicolumn{2}{c}{ Control $(\mathbf{n}=31)$} & \\
\cline { 2 - 4 } & Mean \pm S.D & Mean \pm S.D & p-value \\
\hline Age $(\mathrm{yrs})$ & $50.38 \pm 8.39$ & $52.32 \pm 8.06$ & $0.020^{*}$ \\
Height $(\mathrm{m})$ & $1.62 \pm 0.09$ & $1.63 \pm 0.09$ & 0.436 \\
Body weight $(\mathrm{kg})$ & $73.52 \quad 10.58$ & $69.07 \pm 10.90$ & 0.120 \\
Body mass index $\left(\mathrm{kg} / \mathrm{m}^{2}\right)$ & $28.36 \pm 4.91$ & $25.96 \pm 4.10$ & $0.041^{*}$ \\
Percent body fat $(\%)$ & $39.33 \pm 6.85$ & $34.1 \pm 8.53$ & $0.011^{*}$ \\
Waist circumference $(\mathrm{cm})$ & $97.36 \pm 12.77$ & $92.61 \pm 11.44$ & 0.129 \\
Systolic BP $(\mathrm{mmHg})$ & $155.09 \pm 9.07$ & $159.10 \pm 12.64$ & 0.153 \\
Diastolic BP $(\mathrm{mmHg})$ & $91.13 \pm 9.28$ & $91.26 \pm 12.06$ & 0.961 \\
\hline
\end{tabular}

$*=$ significant 


\section{Blood Pressure}

When comparisons were made among the SBP values at different periods of intervention, Bonferonni correction was carried out to adjust for effect of multiple analyses, and this reduced the significance level (á) to 0.005 . There were significant differences across the periods in exercise group ( $p=0.000$ to 0.002 ) except between week 2 and week 3 , and from week 3 to week 5 (figure 1). In the control group, significant differences were observed only between week 1 and week $2(\mathrm{p}=0.002)$ and week 1 and week $5(p=0.001)$ (figure 1$)$. For the DBP in the exercise group, significant differences were observed between week 1 and week 3 $(\mathrm{p}=0.000)$, week 1 and week $4(\mathrm{p}=0.000)$, week 1 and week $5(\mathrm{p}=0.000)$ and between week 2 and week $3(p=0.003)$, whereas in the control group, significant differences were observed between week 1 and week $3(\mathrm{p}=0.001)$, week 1 and week $4(\mathrm{p}=0.000)$ and week 1 and week $5(\mathrm{p}=0.001)$ (figure 2). After controlling for some covariate, there was no significant change in SBP $(-14.03 \mathrm{mmHg} ; \mathrm{p}=0.064)$ and DBP $(-8.04$ $\mathrm{mmHg} ; \mathrm{p}=0.106)$ between the two groups. Also, the $\mathrm{BP}$ control rates between the exercise $(56.7 \%)$ and control (35.5\%) groups was similar $\left(X^{2}=3.18\right.$; $\mathrm{p}=0.075)$.

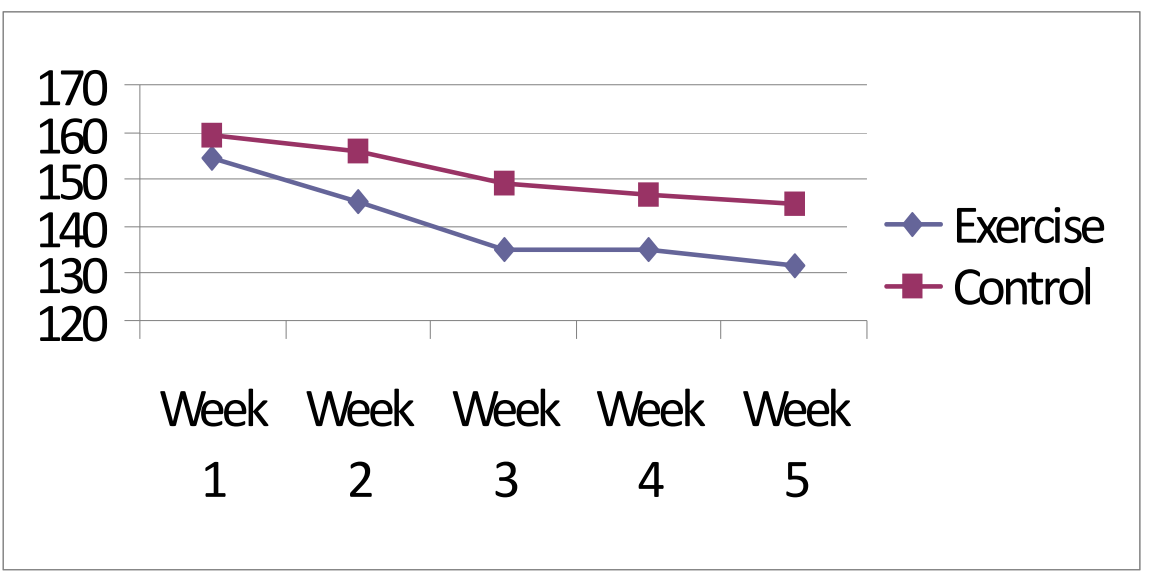

Figure 2: Systolic blood pressure of participants at different periods of the interventions

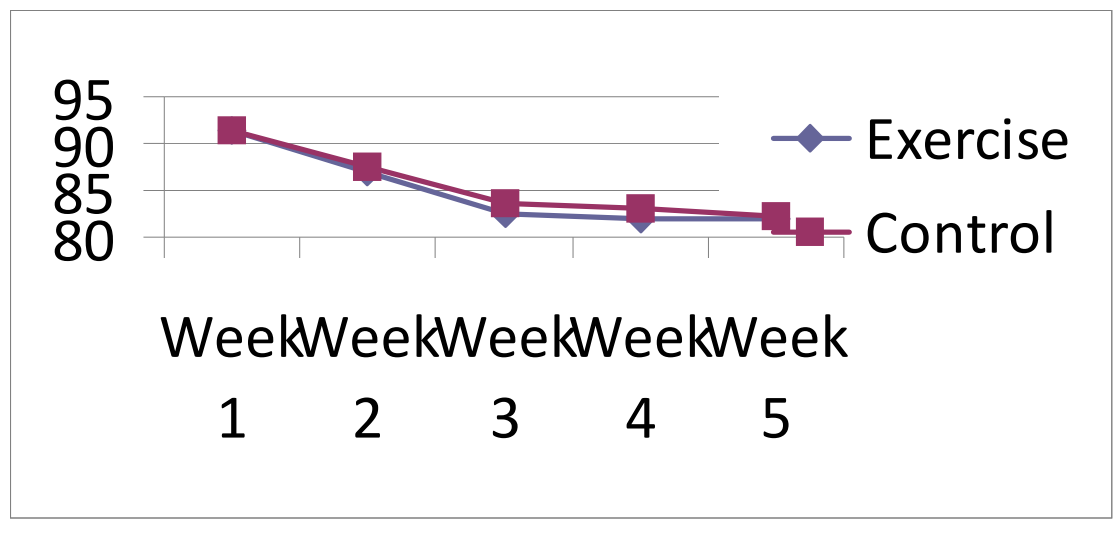

Figure 3: Diastolic BP of participants at different periods of the interventions

\section{Number of drug}

There was no change in number of antihypertensive drugs across the invention periods in the exercise group $(-0.12 ; \mathrm{P}=0.083)$ and the control group $(-0.07$; $\mathrm{P}=0.334)$. Between-group difference in changes in number of antihypertensive drugs was not significant $(-0.016 ; \mathrm{P}=0.511)$.

\section{Study adherence}

Adherence to intervention was similar between the two groups (exercise: 76.97 $\pm 16.50 \%$; control: $\mathrm{p}=73.33 \pm 27.23 \%)(\mathrm{p}=0.529)$. 


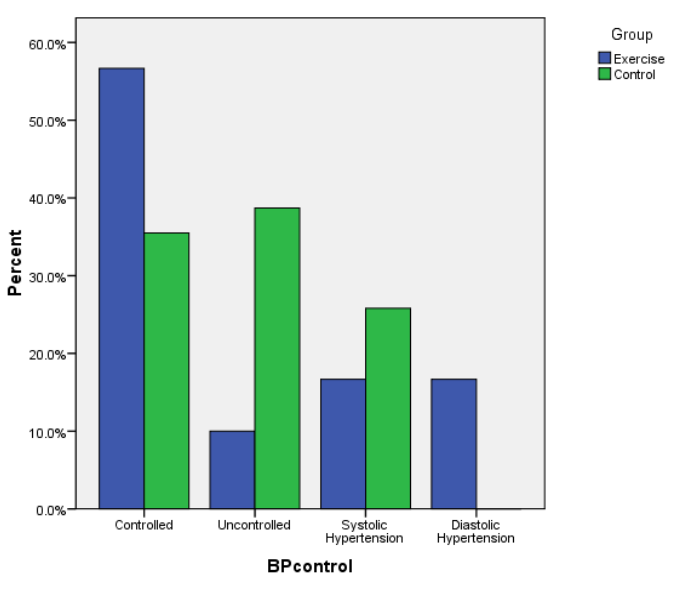

Figure 4: Pattern of BP control in the exercise and control groups

\section{Discussion}

The objectives of this study were to determine the possible additive reducing effect of aerobic exercise, as an adjunct to drug therapy, on BP and number of drugs. Although the BP-lowering effect of aerobic exercise training has been well established $^{17,21,22,}$ its effect on BP control in individuals with hypertension treated with drug therapy but without adequate control is not readily available in the literature. In the present preliminary study, we found that there was no between-group difference in the effects of the two interventions on SBP and DBP. However, BP control rate tended to be higher in the exercise group than the control group after the 12-week intervention. Further, the two groups demonstrated significant reductions in SBP and DBP at some periods of the interventions, although, being more widespread in the exercise group.

There seems to be a dearth of studies examining the possible additive BP-reducing effects of aerobic exercise training to antihypertensive-drug in human being. In a laboratory study, Azevedo et $\mathrm{al}^{25}$ examined the effect of lorsatan combined with exercise training in spontaneously hypertensive rats. They found that lorsatan combined with exercise training had no additional reducing effect on BP compared with lorsatan alone. Also, Minami et al ${ }^{26}$ examined possible additive BP-reducing effects of exercise training, as an adjunct therapy to beta blocker (bisoprolol), in spontaneously hypertensive rats. They found no additive effect of exercise training to BPreducing effects of bisoprolol. Apart from these laboratory studies, Kelemen et al ${ }^{23}$ also investigated possible additive BP-reducing effects of antihypertensive-drug therapy on exercise training in individuals with a history of hypertension. In their study, individuals who were on exercise alone were compared with those on exercise combined with either Propanol Hydrochloride or Diltiazem Hydrochloride. The authors reported that the individuals on exercise alone had no significant change in their BP compared with those on antihypertensive drug combined with exercise after 10-week weight training. Similarly, Radaelli et a ${ }^{24}$ evaluated whether beta-blocker treatment could enhance the BPreducing effects of a mild physical training programme. They reported findings similar to that of Kelemen et $\mathrm{al}^{23}$. Despite the reports of BP reduction following aerobic exercise training ${ }^{15,16}$, only a few patients receive exercise counselling to help lower BP and improve health outcomes. ${ }^{29}$ Apart from the reducing effect on $\mathrm{BP}$, aerobic exercise also has collateral effects on cardiovascular risk factors ${ }^{30}$, and thereby reduce the risk of target organ damage. Based on the tendency of aerobic exercise to reduce SBP and the number of antihypertensive drugs in this study, it is required of healthcare providers to encourage the use of aerobic exercise as an addition. ${ }^{29}$ This is in view of the additional findings of tendency of more participants in the exercise group (56.7\%) than in the control group (35.5\%) attained adequate BP control $(<140 / 90 \mathrm{mmHg})$ post-12-week interventions. Previous studies had reported BP control rates ranging from $28.9 \%$ to $48.7 \%$ in studies on drug therapy alone $e^{9,31,32}$ with a median of $30.5 \% .{ }^{31}$

Blood-pressure monitoring during the intervention showed that the greatest reduction in $\mathrm{BP}$ in the two groups occurred in the first six weeks. A previous report had indicated that a significant effect on BP could be achieved by the eighth week of exercise training. ${ }^{33}$ The finding of a shorter period of achieving a significant $\mathrm{BP}$ reduction in the present study may be attributed to the involvement of antihypertensive drug therapy which may fasten the BP reduction.

Notwithstanding the findings in this preliminary study, it will be premature to make a conclusion from this study. By the time the study is concluded, the results may change with a larger sample size. However, certain limitations in this study need to be noted. Although the average compliance rates in both groups were over $70 \%$, many participants in the two groups did not complete the 12 -week intervention periods, and this may affect the overall outcome of the study. Further, the drugs used in this study were limited to Amlovar (a brand 
of amlodipine) and Normoretic (a brand of diuretic), and the findings in this study may not be extrapolated to other drug brands. This preliminary report presents findings from a smaller sample size than calculated for the study. Although previous studies on exercise and $\mathrm{BP}^{17,18,21}$ had used similar and even smaller sample sizes but with findings of significant reductions in SBP and DBP.

\section{Conclusion}

The findings of no between-group difference in the present intervention, may be due to employment of two potent interventions, which may have a small difference in their effects on BP, and which may require a larger sample size to detect it. Therefore, it would be premature to draw a definitive conclusion from the findings in this study.

\section{Acknowledgements}

This work was supported through African Doctoral Dissertation Research Fellowship offered by the African Population and Health Research Center (APHRC), Kenya in partnership with the International Development Research Centre (IDRC) and Ford Foundation, and Neimeth Pharmaceutical Plc, Nigeria. We thank all participants who volunteered and the staff of Chronic Disease Research Project, University College Hospital, Ibadan, Nigeria, for their assistance.

\section{References}

1. Wolf-Maier K, Cooper RS, Banegas JS, Giampaoli S, Hense H-S, Joffres M, et al. Hypertension prevalence and blood pressure levels in 6 European Countries, Canada, and the United States. Journal of the American Medical Association. 2004; 289(18)

2. Kearney PM, Whelton M, Reynolds K, Muntner PK, He J. Global burden of hypertension: analysis of worldwide data. Lancet. 2005; 365:217-223.

3. Stockwell DH, Madhavan S, Cohen H, Gibson G, Alderson MH. The determinants of hypertension awareness, treatment, and control in an insured population. American Journal of Public Health. 1994; 84(11), 1768-1774

4. Hyman SJ and Pavlick VN. Characteristics of patients with uncontrolled hypertension in the United States. North England Journal of Medicine. 2001; 16; 345(7):479-486.

5. Cushman WC, Ford CE, Cutler JA, Margolis KL, Davis BR, Grimm RH, et al Success and predictors of blood pressure control in diverse North American settings: the antihypertensive and lipid-lowering treatment to prevent heart attack trial (ALLHAT). Journal of Clinical Hypertension (Greenwhich). 2002; 4:393-404

6. Dahlof B, Deverux RB, Kjeldsen SE, Julius S, Beevers G, de Faire U, et al. Cardiovascular morbidity and mortality in the Lorsatan Intervension For Endpoint reduction in hypertension study (LIFE): A randomized trial against atenolol. Lancet. 2002; 359: 995-1003

7. Familoni OB, Ogun SA, Aina OA. Awareness of hypertension and its determinants among hypertensive patients in a Nigerian University Teaching Hospital. Journal of Netherlands University Association. 2004; 96: 620-624

8. Cushman WC. The burden of uncontrolled hypertension: morbidity and mortality associated with disease progression. Journal of Clinical Hypertension. 2003; 5(3 Suppl 2):14-22

9. Yusuff KB \& Balogun O. Physician's prescribing of antihypertensive combination in a tertiary care setting in southwestern Nigeria. Journal of Pharmacological and Pharmaceutical Science. 2005; 8(2): 235-242

10. Kaplan N. Cost Benefit of anti-hypertension therapy. Cardiology Guide. 1991: 2:3-5.

11. Williams B, Poulter NR, Brown MJ, Davis M, McInnes TG, Potter FJ, Sever SP, Thom MS. Education and debate- British Hypertension Society guidelines for hypertension management 2004 (BHS-IV): summary. British Medical Journal. 2004; 328:634-640.

12. Pescatello LS, Franklin BA, Fagard R, Farquhar WB, Kelley GA, Ray CA. American College of Sports Medicine position stand- Exercise and hypertension. Medicine and Science in Sports \& Exercise. 2004; 36(3):533-53

13. Kaplan NM. Treatment of hypertension: insights from the JNCVI Report. American Family Physician. 1998; 58 (6): 1323-1330

14. Vainionpaa A, Korpeleinen R, Kaikonen H, Knip M, Leppaluoto J, Jamsa T. Effect of impact exercise on physical performance and cardiovascular risk factors. Medicine \& S cience in Sports \& Exercise. 2007; 39(5):756-763

15. Brandon LJ, Elliot-Llyod MB. Walking, body composition, and blood pressure dose-response in African-American and white women. Ethnic Disorder. 2006; 16:675-81

16. Lee LL, Arthur A, Avis M. Evaluating a community-based walking intervention for hypertensive older people in Taiwan: a African Health Sciences Vol 13 Issue 1 March 2013 
randomized controlled trial. Preventive Medicine. 2007; 44:160-6

17. Westhoff TH, Schmidt S, Gross V, Joppke M, Zidek W, van der Giet M, Dimeo F. The cardiovascular effects of upper-limb aerobic exercise in hypertensive patients. Journal of Hypertension. 2008; 26:1336-42

18. Tanaka H, Bassett DR Jr, Howley ET, Thompson DLI, Ashraf M, Rawson FL. Swimming training lowers the resting blood pressure in individuals with hypertension. Journal of Hypertension. 1997; 15(6):651-657

19. Farinatti Pde T, Oliveira RB, Pinto VL, Monteiro WD, Franncischetti E. Home exercise program: short-term effects on physical aptitude and blood pressure in hypertensive individuals. Archive of Brazilian Cardiology. 2005; 84:473-9

20. Kumar DP Dancing is good for health: health benefits of dancing. www.saching.com. 2009; Accessed on 25/08/2010

21. Akinpelu AO. Responses of the African hypertensive to exercise training: preliminary observations. Journal of Human Hypertension. 1990; 4:74-76.

22. Dengel DR, Brown MD, Reynolds TH, Kuskowski MA, Supino MA. Effect of aerobic exercise training on blood pressure sensitivity to dietary sodium in older hypertensives. Journal of Human Hypertension. 2006; 20:372-8

23. Kelemen MH, Effron MB, Valenti SA, Stewart KJ. Exercise training combined with antihypertensive drug therapy: effects on lipids, blood pressure, and left ventricular mass. Journal of American Medical Association. 1990; 263(20):2766-2771

24. Radaelli A, Piepoli M, Adamopoulos S, Pipilis A, Clark SJ, Casadei B, et al. Effects of mild physical activity, atenolol and the combination on ambulatory blood pressure in hypertensive subjects. Journal of Hypertension. 1992; 10:12791282

25. Azevedo LF, Brum PC, Mattos KC, Junqueira CM, Rondon MUPB, et al. Effects of losartan combined with exercise training in spontaneously hypertensive rats. Brazilian Journal of Medical and Biological Research. 2003; 36:1595-1603

26. Minami M, Yoshikawa T, Kataoka H, Mori N, Nagasaka M, Kurosawa H, et al. Effects of exercise and beta blockers on blood pressure and baroreflexes in spontaneously hypertensive rats. American Journal of Hypertension. 2003; 16(11 pt 1):966-72.

27. Wilson DK, Kliewer W, Pylobon L, Sica D. Socioeconomic status and blood pressure reactivity in healthy black adolescents. Hypertension. 2000; 35:496-500

28. Kokkinos P, Pittaras A, Narayan P, Faselis C, Singh S, Manolis A. Exercise capacity and blood pressure association with left ventricular mass in prehypertensive individuals. Hypertension. 2007; 49(1): 55-61

29. Halm J, Amoako E. Physical activity recommendation for hypertension management: does healthcare provider advice make a difference? Ethnicity and Disease. 2008; 18:278282

30. Chanudet X, Lambert de Cremeur G, Bonnevie L. Physical activity in hypertension management. La Presse Medicale. 2006; 35:1081-1087

31. Etuk E, Isezuo SA, Chika A, Akuche J, Ali M. Prescription pattern of anti-hypertensive drugs in a tertiary health institution in Nigeria. Annals of African Medicine. 2008; 7(3): 128-132

32. Ordunez P, Barcelo A, Bernal JL, Espinosa A, Silva LC, Cooper RS. Risk factors associated with uncontrolled hypertension: findings from the baseline CARMEN survey in Cienfuegos, Cuba. Journal of Hypertension. 2008; 26:663-671

33. van Sluijs EM, van Poppel MN, Twisk JW, Chin A, Paw MJ, Calfas KJ, Mechelen W. Effect of a tailored physical activity intervention delivered in general practice settings: results off a randomised control trial. American Journal of Public Health. 2005; 95:1825-31

34. Williams PT, Franklin B. Vigorous exercise and diabetic, hypertensive, and hypercholesterolemia medication use. Medicine \& Science in Sports \& Exercise. 2007; 39(11):1933-1941 